\title{
Inhibitory Effects of Korean Red Ginseng and Its Genuine Constituents Ginsenosides Rg3, Rf, and Rh2 in Mouse Passive Cutaneous Anaphylaxis Reaction and Contact Dermatitis Models
}

\author{
Eun-Ah BAE, ${ }^{a}$ Myung Joo Han, ${ }^{a}$ Yong-Wook ShIN, ${ }^{b}$ and Dong-Hyun $\mathrm{KIM}^{*}, b$ \\ ${ }^{a}$ Department of Food and Nutrition, Kyung Hee University; and ${ }^{b}$ College of Pharmacy, Kyung Hee University; 1 Hoegi, \\ Dongdaemun-ku, Seoul 130-701, Korea. Received November 16, 2005; accepted April 28, 2006
}

The inhibitory effects of the Korean red ginseng (steamed root of Panax ginseng C.A. MEYER, family Araliaceae) saponin fraction (KRGS) and its constituents ginsenosides Rg3, Rf, and Rh2 in mouse passive cutaneous anaphylaxis (PCA) and contact dermatitis models were measured. Orally administered KRGS and its genuine ginsenosides potently inhibited the PCA reaction induced by IgE. However, when these ginsenosides were intraperitoneally administered, ginsenoside Rh2 showed the most potent inhibition. The ginsenoside Rh2 also the most potently inhibited the $\beta$-hexosaminidase release from RBL-2H3 cells induced by IgE with antigen. KRGS administered topically at a dose of $0.1 \%$ suppressed ear swelling in an oxazolone-induced mouse contact dermatitis model by $38.8 \%$. Its constituents ginsenosides $\mathrm{Rg} 3$, Rf, and $\mathrm{Rh} 2$ at a concentration of $0.05 \%$ also potently suppressed mouse ear swelling by $47.5 \%, 34.8 \%$, and $49.9 \%$ at $16 \mathrm{~d}$, respectively. These ginsenosides also significantly reduced mRNA expression levels of cyclooxygenase (COX)-2, interleukin (IL)-1 $\beta$, tumor necrosis factor- $\alpha$ and interferon- $\gamma$ induced by oxazolone applied to mouse ears. However, the ginsenosides, except for ginsenoside Rh2, almost did not notably reduce IL-4 levels. The ginsenoside Rh2 also potently inhibited COX-2 and inducible NO synthetase protein expression in liphopolysaccharide-stimulated RAW264.7 cells. Based on these findings, KRGS and its ginsenosides are suggested to improve atopic and contact dermatitis by regulating expression of cytokines.

Key words Korean red ginseng; ginsenoside Rf; ginsenoside Rh2; antiallergic activity; antipsoriatic activity

Korean red ginseng (KRG, the steamed root of Panax ginseng C.A. MEYER, family Araliaceae) is frequently used as a crude substance taken orally in Asian countries as a traditional medicine. The major components of raw ginseng are ginsenosides, which contain an aglycone with a dammarane skeleton. ${ }^{1,2)}$ Many types of saponins, such as ginsenosides $\mathrm{Rb} 1, \mathrm{Rb} 2, \mathrm{Rc}$, and Rf, have been isolated. The ginsenosides $\mathrm{Rg} 3, \mathrm{Rf}$, and $\mathrm{Rh} 2$ are genuine saponins in KRG and heatprocessed ginseng. ${ }^{3,4)}$ Ginsenosides Rg3 and Rh2 were produced from protopanaxadiol ginsenosides by steaming to prepare KRG. ${ }^{5)}$

Psoriasis is a chronic inflammatory skin disorder. Psoriasis patients have been shown to have interferon (IFN)- $\gamma$ producing Th1 bias in lesion skin and peripheral blood and are thought to develop cytokine networks of Th1 cells, resulting in keratinocyte hyperplasia and angiogenesis. ${ }^{6,7)}$ Cylcooxygenase (COX)-2 is also induced in angiogenesis-related diseases such as rheumatoid arthritis and psoriasis. ${ }^{8)}$ Fujii et al. developed an oxazolone-induced animal model of experimental psoriasis. ${ }^{9)}$ This psoriatic animal model is a chronic inflammation model and significantly induces the expression levels of COX-2 and inducible NO synthase (iNOS) in monocytes and macrophages and IFN- $\gamma$ and interleukin (IL)4 in Th cells. The ginsenosides have been reported to show various biological activities including antiinflammatory activity, antiallergic, endothelium-independent aorta relaxation, and antitumor effects. ${ }^{10-13)}$ Tachikawa et al. reported that ginsenoside $\mathrm{Rg} 3$ suppressed histamine release from mast cells due to stimulation with compoumd $48 / 80$ in vitro, ${ }^{14)}$ and Ro et al. reported that ginsenosides $\mathrm{Rb} 1$ and $\mathrm{Rc}$ also partly inhibited the release of histamine and leukotrienes during the activation of guinea pig lung mast cells in vitro. ${ }^{15)}$ We also reported the antiallergic and antiinflammatory effects of ginsenoside Rh1, antiallergic and passive cutaneous anaphylaxis
(PCA) reaction-inhibitory effects of compound $\mathrm{K}$, and antiallergic effects of ginsenoside Rh2. ${ }^{16-18)}$ However, the antiallergic and antipsoriatic effects of KRG and genuine ginsenoside $\mathrm{Rf}$ have not been thoroughly studied. We therefore investigated the PCA reaction-inhibitory and antiallergic and antipsoriatic effects of the KRG saponin fraction (KRGS) and its constituents ginsenosides $\mathrm{Rg} 3, \mathrm{Rf}$, and $\mathrm{Rh} 2$.

\section{MATERIALS AND METHODS}

Materials $p$-Nitrophenyl- $N$-acetyl- $\beta$-D-glucosaminide, Freund's complete adjuvant, anti-dinitrophenol (DNP)-IgE, DNP-human serum albumin (HSA), lipopolysaccharide (LPS), Evans blue, disodium cromoglycate (DSCG), trichloroacetic acid, betamethasone, and azelastine were purchased from Sigma Chemical Co. (St. Louis, MO, U.S.A.). KRG water extract, ginsenoside $\mathrm{Rf}$, and ginsenoside $\mathrm{Rh} 2$ were donated by KT\&G (Seoul, Korea). KRGS and ginsenoside $\mathrm{Rg} 3$ were prepared according to our previous method. ${ }^{6}$ KRGS, which is the $\mathrm{BuOH}$ fraction of $\mathrm{KRG}$, contains ginsenosides $\mathrm{Rb} 1$ (16.3\%), Rf (7.4\%), Rg3 (4.6\%), and Rh2 $(0.1 \%)$ as the main constituents.

Assay of Antiallergic Activity in the RBL $2 \mathrm{H3}$ Cell Line The inhibitory activity of KRGS and its genuine ginsenosides against the release of $\beta$-hexosaminidase from RBL-2H3 cells was evaluated according to the method of Choi et al. ${ }^{19)}$ RBL-2H3 cells were grown in Dulbecco's modified Eagle medium supplemented with 10\% fetal bovine serum and L-glutamine and split every $3 \mathrm{~d}$. Before the experiment, cells were dispensed into 24 -well plates $\left(5 \times 10^{5}\right.$ cells per well) using medium containing $0.5 \mu \mathrm{g} / \mathrm{ml}$ of mouse monoclonal IgE and incubated overnight at $37^{\circ} \mathrm{C}$ in $5 \% \mathrm{CO}_{2}$ for sensitization. The cells were washed with $500 \mu \mathrm{l}$ of siraganian buffer ( $\mathrm{pH} 7.2, \mathrm{NaCl} 119 \mathrm{~mm}, \mathrm{KCl} 5 \mathrm{~mm}, \mathrm{MgCl}_{2} 0.4 \mathrm{~mm}$, 
piperazine- $N, N$-bis(2-ethanesulfonic acid) $25 \mathrm{~mm}, \mathrm{NaOH} 40$ $\mathrm{mm}$ ) and incubated in $160 \mu \mathrm{l}$ of siraganian buffer containing glucose $5.6 \mathrm{~mm}, \mathrm{CaCl}_{2} 1 \mathrm{~mm}$, and $0.1 \%$ bovine serum albumin for an additional $10 \mathrm{~min}$ at $37^{\circ} \mathrm{C}$. Then cells were exposed to $40 \mu \mathrm{l}$ of test agents for $20 \mathrm{~min}$, followed by the treatment with $20 \mu \mathrm{l}$ of antigen (DNP-HSA, $1 \mu \mathrm{g} / \mathrm{ml}$ ) for 10 min at $37^{\circ} \mathrm{C}$ to activate cells to evoke allergic reactions. The reaction was stopped by cooling in an ice bath for $10 \mathrm{~min}$. The reaction mixture was centrifuged at $800 \times \boldsymbol{g}$ for $10 \mathrm{~min}$ and $25 \mu \mathrm{l}$ aliquots of supernatant were transferred to 96 -well plates and incubated with $25 \mu \mathrm{l}$ of substrate ( $p$-nitrophenyl$N$-acetyl- $\beta$-D-glucosaminide $1 \mathrm{~mm}$ ) for $1 \mathrm{~h}$ at $37^{\circ} \mathrm{C}$. The reaction was stopped by adding $200 \mu \mathrm{l}$ of $\mathrm{Na}_{2} \mathrm{CO}_{3} / \mathrm{NaHCO}_{3}$ $0.1 \mathrm{M}$, ( $\mathrm{pH} 10.5)$ The absorbance was measured with an ELISA microplate reader at $405 \mathrm{~nm}$.

Animals Male and female ICR mice $(20-25 \mathrm{~g})$ were supplied by the Orient Charles River Experimental Animal Breeding Center (Seoul, Korea). All animals were housed in wire cages and fed with standard laboratory chow (Orient Charles River Feed Production Co., Seoul, Korea) and water ad libitum. All procedures relating to animals and their care conformed to the international guidelines on Principles of Laboratory Animal Care (NIH publication no. 85-23, revised 1985).

PCA Reaction The IgE-dependent cutaneous reaction was measured according to the previous method of Katayama et $a{ }^{20)}$ Male ICR mice $(25-30 \mathrm{~g})$ were injected intradermally with $10 \mu \mathrm{g}$ of anti-DNP IgE into each of two dorsal skin sites that had been shaved $48 \mathrm{~h}$ earlier. The sites were outlined with a water-insoluble red marker. Forty-eight hours later, each mouse received an injection of $200 \mu \mathrm{l}$ of $3 \%$ Evans blue in phosphate-buffered saline containing $200 \mu \mathrm{g}$ of DNP-HSA via the tail vein. The test agents were administered $1 \mathrm{~h}$ prior to DNP-HSA injection. Thirty minutes after DNP-HSA injection, the mice were killed and their dorsal skins were removed for measurement of the pigmented area $(1 \times 1 \mathrm{~cm})$. After extraction with $1 \mathrm{ml}$ of $1.0 \mathrm{~N} \mathrm{KOH}$ and $4 \mathrm{ml}$ of a mixture of acetone and $0.6 \mathrm{~N}$ phosphoric acid (13:5), the amount of dye was determined colorimetrically (absorbance at $620 \mathrm{~nm})$.

Contact Hypersensitivity Oxazolone-induced dermatitis was measured according to the method of Fujii et al. ${ }^{21)}$ Female ICR mice were sensitized by the application of $100 \mu \mathrm{l}$ of $1.5 \%$ oxazolone in ethanol to the abdomen. Then a total of $20 \mu \mathrm{l}$ of $1 \%$ oxazolone in a mixture of acetone and olive oil (4:1) was applied to both sides of the mouse ear every $3 \mathrm{~d}$ starting from $7 \mathrm{~d}$ after sensitization. Ear thickness was measured using a Digimatic Micrometer (Mitsutoyo Co., Tokyo, Japan). Test agents were applied in a total volume of $20 \mu \mathrm{l}$ to both sides of the ear $30 \mathrm{~min}$ before and $3 \mathrm{~h}$ after each application of oxazolone.

RT-PCR Analysis Ear tissue extraction for RT-PCR analysis was performed using the modified method of Chi et $a l .^{22)}$ Briefly, ears were excised $6 \mathrm{~h}$ after the last application of oxazolone, frozen in liquid nitrogen, and homogenized with a mortar and pestle prechilled in liquid nitrogen. Total RNA was extracted using TRI Reagent (Molecular Research Center, Inc., Cincinnati, OH, U.S.A.) according to the manufacturer's instructions and treated with RNase-free DNase. The concentration of RNA was determined by measuring the absorbance at 260 and $280 \mathrm{~nm}$, and tissue were stored at
$-70{ }^{\circ} \mathrm{C}$ until RT-PCR analysis. RT-PCR was performed with AccPower RT/PCR Premix (Bioneer, Seoul, Korea). The primers were designed as described in the UniSTS database: COX-1, forward primer 5'-CTTTTATCCTCCCAGGATTTGG-3 and reverse primer 5'-GCTAAATACTTTGACACCGG-3' (product size $231 \mathrm{bp}$ ); COX-2, forward primer 5'-TGTATCCCCCCACAGTCAAAGACAC-3' and reverse primer 5'-GTGCTCCCGAAGCCAGATGG-3' (product size $146 \mathrm{bp})$; IL-1 $\beta$, forward primer $5^{\prime}$-ATGGCAACTGTCC CTGAACT-3' and reverse primer 5'-GTCGTTGCTTGTCTCTCCTT-3' (product size $508 \mathrm{bp}$ ); IFN- $\gamma$, forward primer 5'-CTTTAACAGCAGGCCAGACA-3' and reverse primer 5'-GCGAGTTATTTGTCATTCGG-3' (product size $144 \mathrm{bp}$ ); IL-4, forward primer 5'-CCGATTATGGTGTAATTTCCTATGCTG-3' and reverse primer 5'-GGCCAATCAGCACCTCTCTTCCAG-3' (product size $111 \mathrm{bp}$ ); tumor necrosis factor (TNF)- $\alpha$, forward primer $5^{\prime}$-GATTTTATTTGTTTAAAAGCAGATATC- $3^{\prime}$ and reverse primer 5'-CATCCTAAGTCTA CACAGGATCT-3' (product size 206 bp); glyceraldehyde-3phosphate dehydrogenase (GAPDH), forward primer $5^{\prime}-\mathrm{AC}$ CACAGTCCATGCCATCAC-3' and reverse primer 5'-TCCACCACCCTGTTGCTGTA-3' product size $452 \mathrm{bp}$ ). The amplification was performed at $94^{\circ} \mathrm{C}$ for $30-60 \mathrm{~s}$, and 49 $62^{\circ} \mathrm{C}$ for $30-40 \mathrm{~s}$, and $72{ }^{\circ} \mathrm{C}$ for $30-60 \mathrm{~s}$ with 30 cycles for COX-1, IL- $1 \beta$, TNF- $\alpha$ and GAPDH, and 32 cycles for other genes, in $20 \mu \mathrm{l}$ of reaction mixture. The RT-PCR products were electrophoresed on $2 \%$ agarose gel in Tris-borate-ethylenediaminetetraacetic acid (TBE) buffer, stained with ethidium bromide, and photographed under UV light. The mRNA of GAPDH was used as an internal control. The signal intensity of each RT-PCR product was estimated using a Shimadzu 9301-PC scanner (Shimadzu Co., Tokyo, Japan).

Culture of RAW264.7 Cells and Immunoblot Analysis Immunoblot analyses of iNOS, COX-2, and nerve factorkappaB $(\mathrm{NF}-\kappa \mathrm{B})$ were performed according to the method of Ishihara et $a l .{ }^{23)}$ The RAW264.7 cells were plated in $60 \mathrm{~mm}$ culture dishes $\left(3 \times 10^{6}\right.$ cells $)$, test agents and LPS $(1 \mu \mathrm{g} / \mathrm{ml})$ added to the culture medium, and the cells were incubated at $37^{\circ} \mathrm{C}$ for $6-20 \mathrm{~h}$. The cells were lysed on ice for $15 \mathrm{~min}$ in a hypotonic buffer, containing Tris $10 \mathrm{~mm}(\mathrm{pH} 8.0), \mathrm{MgCl}_{2}$ $1.5 \mathrm{~mm}$, dithiothreitol $1 \mathrm{~mm}, 0.1 \% \mathrm{NP}-40$, pepstatin A $5 \mu \mathrm{g} / \mathrm{ml}$, and aprotinin $5 \mu \mathrm{g} / \mathrm{ml}$ and centrifuged at $12000 \times \boldsymbol{g}$ and $4{ }^{\circ} \mathrm{C}$ for $15 \mathrm{~min}$. The supernatant was used as the cytosol fraction for the immuoblot assays for iNOS and COX-2 protein expression. The pelleted nuclei fractions for the immunoblot assays of NF- $\kappa \mathrm{B}$ protein expression were resuspended in the extraction buffer containing Tris $10 \mathrm{~mm}(\mathrm{pH}$ 8.0), $\mathrm{KCl} 50 \mathrm{~mm}, \mathrm{NaCl} 300 \mathrm{~mm}$, dithiothreitol $1 \mathrm{~mm}$, pepstatin A $5 \mu \mathrm{g} / \mathrm{ml}$, and aprotinin $5 \mu \mathrm{g} / \mathrm{ml}$ and then lysed on ice for $30 \mathrm{~min}$. The lysed nuclei fraction was centrifuged at $12000 \times \boldsymbol{g}$ and $4{ }^{\circ} \mathrm{C}$ for $30 \mathrm{~min}$. Protein expression levels of $\mathrm{COX}-2, \mathrm{iNOS}, \mathrm{NF}-\kappa \mathrm{B}$, and $\beta$-actin in the cell lysates $(40 \mu \mathrm{g})$ were analyzed using the above immunoblot method.

Statistics All the data are expressed as the mean \pm standard error, and statistical significance was analyzed by oneway ANOVA followed by the Student-Newman-Keuls test.

\section{RESULTS}

Inhibition by KRGS and Its Ginsenosides of $\beta$-Hexosaminidase Release from RBL-2H3 Cells To investigate 
whether KRGS and its genuine ginsenosides possess antiallergic activity, we examined their inhibitory effects against $\beta$ hexosaminidase release (degranulation) from RBL-2H3 cells induced by IgE with antigen (Table 1). Ginsenosides Rf and $\mathrm{Rh} 2$ potently inhibited $\beta$-hexosaminidase release from RBL$2 \mathrm{H} 3$ cells induced by $\mathrm{IgE}$, with $\mathrm{IC}_{50}$ values of 0.08 and $0.03 \mathrm{~mm}$, respectively, and the results were comparable those of azelastine. However, KRGS and ginsenoside $\mathrm{Rg} 3$ only weakly inhibited the degranulation of RBL-2H3 cells.

Inhibition of the PCA Reaction by KRGS and Its Ginsenosides The PCA reaction in sensitized mice was induced by the intradermal injection of DNP-HSA, KRGS or its constituents were administered orally or intraperitoneally 60 min prior to challenge with DNP-HSA antigen, and their inhibitory potency against the PCA reaction was measured (Table 2). KRGS orally administered at a dose of $500 \mathrm{mg} / \mathrm{kg}$ potently inhibited the PCA reaction. Orally and administered intraperitoneally ginsenosides $\mathrm{Rf}, \mathrm{Rg} 3$, and $\mathrm{Rh} 2$ also significantly inhibited the PCA reaction. The inhibitory potency of these ginsenosides intraperitoneally administered at a dose of $25 \mathrm{mg} / \mathrm{kg}$ was greater than that when orally administered. The inhibitory effects of these ginsenosides were more potent than that of DSCG, but was inferior to that of azelastine. Among tested ginsenosides, ginsenoside $\mathrm{Rh} 2(25 \mathrm{mg} / \mathrm{kg})$ showed the most potent (63\%) inhibition.

Inhibition by KRGS and Its Ginsenosides of Ear

Table 1. Inhibitory Effects of Ginsenosides on $\beta$-Hexosaminidase Release from RBL $2 \mathrm{H} 3$ Cells Induced by IgE with DNP-HSA

\begin{tabular}{lc}
\hline \multicolumn{1}{c}{ Group } & $\mathrm{IC}_{50}(\mathrm{mM})$ \\
\hline KRGS $^{a}$ ) & 0.32 \\
Ginsenoside Rf & 0.08 \\
Ginsenoside Rg3 & 0.24 \\
Ginsenoside Rh2 & 0.03 \\
Azelastine & 0.03 \\
Disodium cromoglycate & 0.50
\end{tabular}

$\beta$-Hexosaminidase activity (\%) released from RBL $2 \mathrm{H} 3$ cells induced by IgE with DNP-HSA was $65.0 \pm 6.5 \%$. a) Concentration of KRGS, which is the $\mathrm{BuOH}$ fraction of Korean Red Ginseng, is in $\mathrm{mg} / \mathrm{ml}$.
Swelling in Oxazolone-Induced Mouse Ear Dermatitis In the preliminary experiment, KRGS suppressed the swelling of oxazolone-induced mouse ear dermatitis after topical administration (Fig. 1). Therefore we also measured the effects of its genuine saponin ginsenosides $\mathrm{Rf}, \mathrm{Rg} 3$, and $\mathrm{Rh} 2$. Oxazolone applied to the ears of sensitized mice caused erythema (reddening of the skin), edema, and/or induration, and sometimes abrasion. When the ear thickness was measured as an index of skin inflammation, it increased with repeated application, and reached the maximum $16 \mathrm{~d}$ after sensitization. Dermatitis persisted for $2 \mathrm{~d}$ and then slowly declined. Betamethasone used as a positive agent at the concentration of $0.05 \%$ suppressed ear swelling by $75 \%$ at $16 \mathrm{~d}$. The ginsenosides $\mathrm{Rf}, \mathrm{Rg} 3$, and $\mathrm{Rh} 2$ at a concentration of $0.05 \%$ also inhibited the swelling after oxazolone sensitization at $16 \mathrm{~d}$ by $34.8 \%, 47.5 \%$, and $49.9 \%$, respectively, compared with oxazolone-alone control group. For histopathologic analysis, we excised ears at $16 \mathrm{~d}$ and stained them with hematoxylin-eosin (Fig. 2). The ears sensitized with oxa-

Table 2. Inhibitory Effects of Ginsenosides and Disodium Cromoglycate on the Passive Cutaneous Anaphylaxis Reaction

\begin{tabular}{lccc}
\hline \hline \multirow{2}{*}{ Group } & & \multicolumn{2}{c}{ Inhibition (\%) } \\
& Dose $(\mathrm{mg} / \mathrm{kg})$ & p.o. & i.p. \\
\cline { 3 - 4 } & & $3 \pm 2.1^{a)}$ & $2 \pm 3.4^{a)}$ \\
Vehicle alone & - & $32 \pm 4.8^{c)}$ & $\left.-{ }^{b}\right)$ \\
KRGS & 100 & $61 \pm 5.1^{d)}$ & - \\
Ginsenoside Rf & 500 & - & $\left.30 \pm 7.5^{c, d}\right)$ \\
Ginsenoside Rg3 & 10 & $34 \pm 5.2^{c)}$ & $54 \pm 6.2^{e, f)}$ \\
Ginsenoside Rh2 & 25 & - & $22 \pm 3.8^{c)}$ \\
Azelastine & 10 & $38 \pm 9.4^{c)}$ & $47 \pm 11.5^{d)}$ \\
DSCG & 10 & - & $31 \pm 9.8^{c, d)}$ \\
& 25 & $36 \pm 7.7^{c)}$ & $63 \pm 6.5^{f)}$ \\
& 10 & $81 \pm 4.3^{e)}$ & $88 \pm 5.6^{g)}$ \\
& 100 & $37 \pm 0.2^{c)}$ & $48 \pm 6.5^{d, e)}$ \\
\hline
\end{tabular}

All agents were administered p.o. or i.p. prior to challege with antigen. Each experiment consisted of six observations. The amounts of dye detected in mice without the PCA reaction and that in control mice were $0.21 \mu \mathrm{g}$ and $0.75 \mu \mathrm{g}$, respectively. $b$ ) Not determined. $a, c, d, e, f, g)$ Those with the same letter are not significantly different in each column $(p<0.05)$.

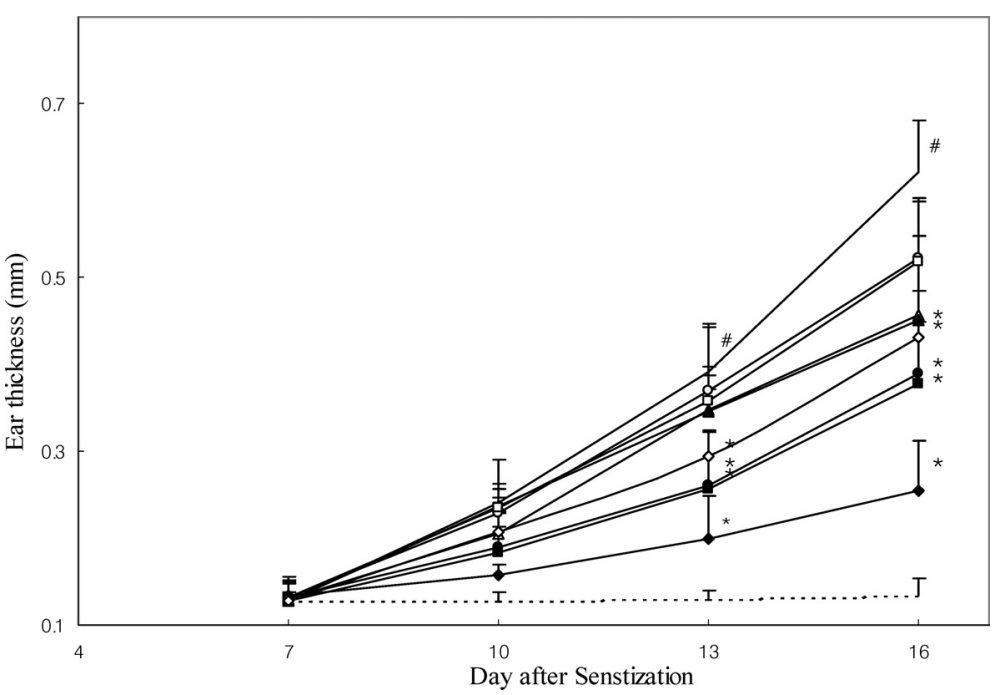

Fig. 1. Effects of KRGS and Its Ginsenosides on the Ear Thickness of Mice Induced by Oxazolone

---, vehicle alone (normal) control; - , oxazolone alone-treated control; $\diamond, 0.1 \%$ KRGS; $\bigcirc, 0.02 \%$ ginsenoside Rg3;, $0.05 \%$ ginsenoside Rg3; $\triangle$, $0.02 \%$ ginsenoside Rf; $\boldsymbol{\Delta}$, $0.05 \%$ ginsenoside Rf; $\square, 0.02 \%$ ginsenoside Rh2; $\mathbf{\square}, 0.05 \%$ ginsenoside Rh2; $\bullet, 0.05 \%$ betamethasone. Values represent mean \pm S.E. for 6 mice. \# Significantly different from the oxazolone-treated (control) group ( $\# p>0.05$ ). 
A
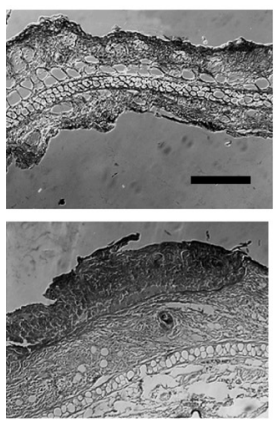

F
B
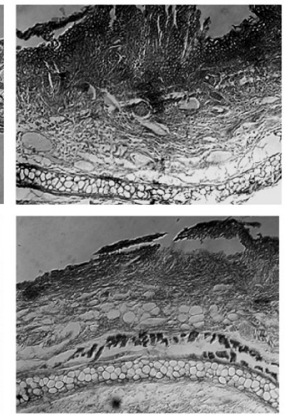

G
C
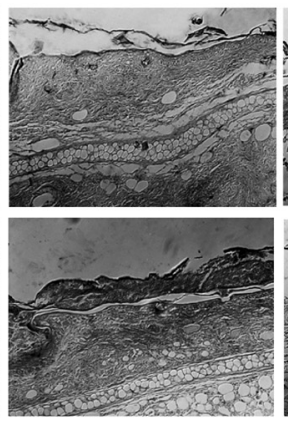

$\mathrm{H}$
D

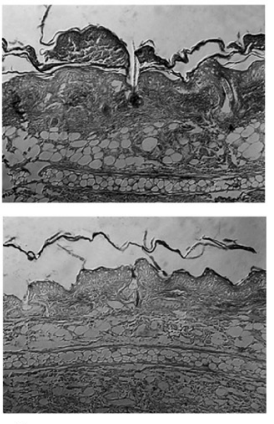

I
E
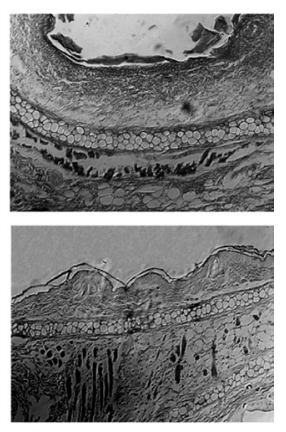

J

Fig. 2. Histopathology of Mouse Ear after Repeated Application of Oxazolone with or without KRGS, Its Ginsenosides, or Betamethasone

Mouse ears were excised $72 \mathrm{~h}$ after the final application of oxazolone and stained with hematoxylin-eosin. As a negative control, mice were sensitized with $1.5 \%$ oxazolone alone on the abdomen followed by no application to the ear (A). 1\% oxazolone and vehicle (ethanol) were applied to both sides of the ear every $3 \mathrm{~d}$ starting from $7 \mathrm{~d}$ after sensitization (B). $0.1 \%$ KRGS (C), 0.02\% ginsenoside Rg3 (D), 0.05\% ginsenoside Rg3 (E), $0.02 \%$ ginsenoside Rf (F), $0.05 \%$ ginsenoside Rf (G), $0.02 \%$ ginsenoside Rh2 (H), $0.05 \%$ ginsenoside $\mathrm{Rh} 2$ (I) or $0.05 \%$ betamethasone (J) was applied to the ear $30 \mathrm{~min}$ before and $3 \mathrm{~h}$ after each application of oxazolone. The scale bar in (A) is $0.1 \mathrm{~mm}$.

zolone swelled markedly and sometimes showed abrasion. Oxazolone-sensitized ears could not be stained throughout the entire section. However, the ginsenosides reduced the thickness of swollen ears after the application of oxazolone. The ginsenosides also improved the abrasion and swelling. Nevertheless, the effects of these ginsenosides were inferior to that of betamethasone.

Effects of KRGS and Its Ginsenosides on mRNA Expression Levels of COXs and Cytokines in Oxazolone-Induced Mouse Ear Dermatitis The effect of KRGS and its genuine ginsenosides on mRNA expression levels of COX-1, COX-2, and some cytokines in mouse ear dermatitis induced by oxazolone was investigated using RT-PCR analysis (Fig. 3). Oxazolone significantly induced the mRNA expression of COX-2. However, it did not induce that of COX-1. When oxazolone-treated mice were treated with KRGS and its ginsenosides, these agents did not affect the COX-1 mRNA expression. However, KRGS and its ginsenosides inhibited mRNA expression levels of COX-2. Among them, ginsenoside Rh2 most potently inhibited the mRNA expression of COX-2. Oxazolone significantly induced mRNA expression of TNF- $\alpha$ and IL- $1 \beta$, which are produced by macrophages or monocytes, and IFN- $\gamma$ and IL-4, which are produced by Th1 and Th2 cells. KRGS and its ginsenosides potently inhibited mRNA expression of IL- $1 \beta$, IFN- $\gamma$, and TNF- $\alpha$, although that of IL-4 was only weakly inhibited. Among these ginsenosides, ginsenoside Rh2 exhibited the most potent inhibition.

Effects of KRGS and Its Ginsenosides on iNOS and COX-2 Protein Expression and NF- $\kappa$ B Activation in LPSInduced RAW264.7 Cells Immunoblot analysis was also used to determine whether KRGS could affect the protein expressions of iNOS and COX-2 (Fig. 4). Stimulation of RAW 264.7 cells with LPS not only increased the expression levels of iNOS and COX-2 proteins, but also increased the activated transcription factor $\mathrm{NF}-\kappa \mathrm{B}, \mathrm{p} 65$, in the nuclei of the cells. KRGS only slightly reduced iNOS and COX-2 protein levels, although KRGS weakly inhibited the activation of transcription factor NF- $\kappa \mathrm{B}$ in the nuclei of RAW264.7 cells stimulated with LPS. The effects of its ginsenosides were also investigated. The ginsenosides inhibited iNOS and COX-2 protein expression and reduced activated NF- $\kappa \mathrm{B}$ p65
(A)

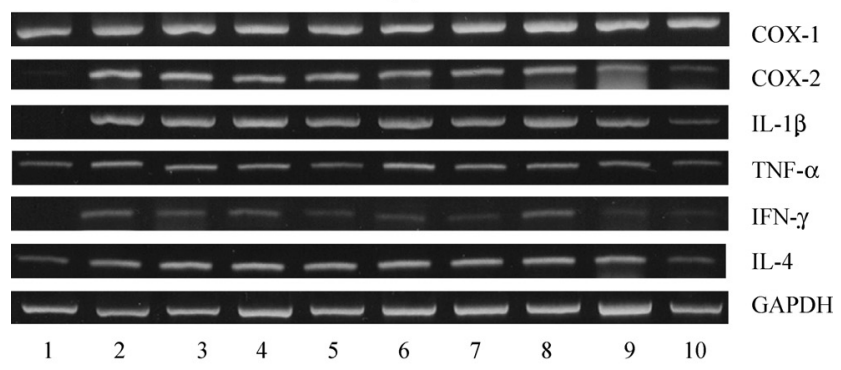

(B)
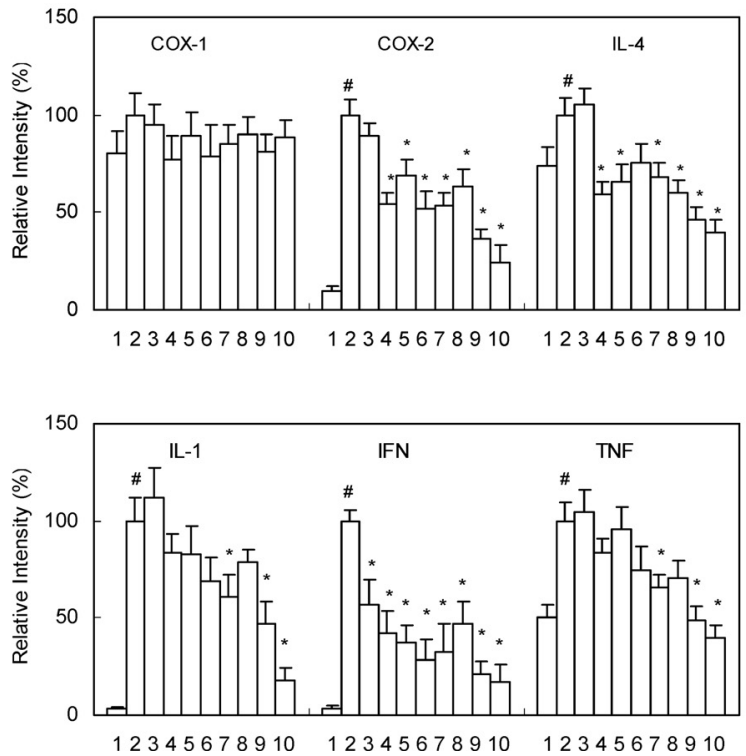

Fig. 3. Effects of KRGS and Its Ginsenosides on COX-1, COX-2, IL-1 $\beta$, IL-4, INF- $\gamma$, TNF- $\alpha$, and GAPDH mRNA Expression Levels in OxazoloneInduced Mouse Ear Dermatitis

(A) RT-PCR products; (B) relative density (\%) of RT-PCR products [COX-1, COX-2, IL-4, IL-1 $\beta$ (IL-1), IFN- $\gamma$ (IFN), or TNF- $\alpha$ (TNF)/GAPDH]. Mouse ears were excised $72 \mathrm{~h}$ after the final application of oxazolone and stained with hematoxylin-eosin. As a negative control, mice were sensitized with $1.5 \%$ oxazolone alone on the abdomen followed by no application to the ear (1). $1 \%$ oxazolone and vehicle (ethanol) was applied to both sides of the ear every $3 \mathrm{~d}$ starting from $7 \mathrm{~d}$ after sensitization (2). 1, normal control; 2, treated with oxazolone alone; 3 , treated with $0.1 \%$ KRGS with oxazolone; 4 , treated with $0.05 \%$ ginsenoside $\mathrm{Rf}$ and oxazolone; 5 , treated with $0.1 \%$ ginsenoside $\mathrm{Rf}$ and oxazolone; 6 , treated with $0.05 \%$ ginsenoside $\mathrm{Rg} 3$ with oxazolone; 7 , treated $0.1 \%$ ginsenoside Rg3 and oxazolone; 8 , treated with $0.05 \%$ ginsenoside $\mathrm{Rh} 2$ and oxazolone; 9 , treated with $0.1 \%$ ginsenoside $\mathrm{Rh} 2$ and oxazolone; 10 , treated with $0.05 \%$ betamethasone and oxazolone. 
(A)

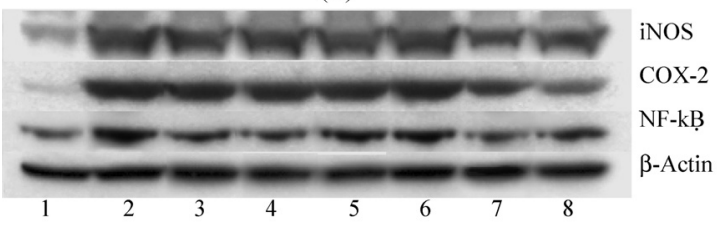

(B)

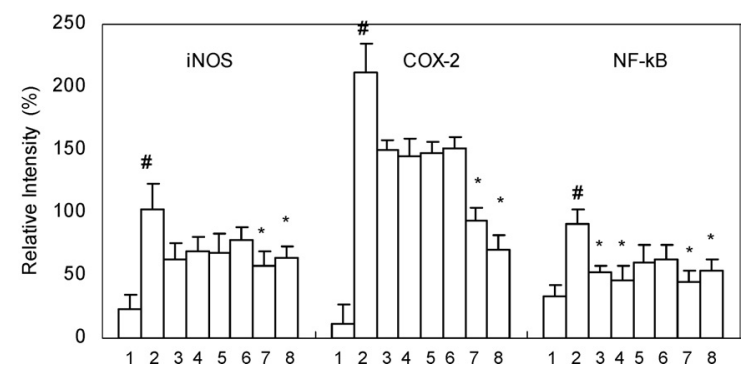

Fig. 4. Effects of KRGS and Its Ginsenosides on iNOS, COX-2 and NF$\kappa \mathrm{B}$ Protein Expression Levels of RAW264.7 Cells Treated with Lipopolysaccharides (LPS)

(A) Immunoblot; (B) relative intensity (\%) of immunoblots (iNOS, COX-2, or NF$\kappa \mathrm{B} / \beta$-actin). 1, normal control; 2 , LPS alone; 3 , KRGS $20 \mu \mathrm{g} / \mathrm{ml}$ with LPS; 4 , ginsenoside Rf $20 \mu \mathrm{M}$ with LPS; 5, ginsenoside Rg3 $20 \mu \mathrm{m}$ with LPS; 6 , ginsenoside Rh2 $4 \mu \mathrm{M}$ with LPS; 7 , ginsenoside Rh2 $20 \mu \mathrm{m}$ with LPS; 8 , betamethasone $20 \mu \mathrm{m}$ with LPS.

in the nuclei fraction induced by LPS. Ginsenoside Rh2 the most potently inhibited the protein expression of iNOS and COX -2 and reduced the activated transcription factor NF $-\kappa \mathrm{B}$ in the nuclei of the RAW264.7 cells. The reduced levels of $\mathrm{NF}-\kappa \mathrm{B}$ p 65 protein were correlated with those of iNOS and COX-2 protein expression.

\section{DISCUSSION}

Allergic diseases such as asthma, allergic rhinitis, atopic dermatitis, and food allergy afflict up to $20 \%$ of the human population in most countries. ${ }^{24)}$ The etiology of allergy reactivity is based on IgE-medicated pharmacologic processes in a variety of cell populations such as mast cells and basophils. ${ }^{25)}$ Degradation of mast cells and basophils with antigen-crosslinked IgE releases histamine, prostaglandins, leukotrienes, and cytokines affecting lymphocytes, macrophages, eosinophils, and neutrophils. Finally a cytokine-induced reaction causes tissue injury such as chronic dermatitis or psoriasis. Therefore antiallergic agents with antiinflammatory or antipsoriatic actions may be beneficial in the treatment of allergic diseases.

KRGS inhibited the PCA reaction induced by $\operatorname{IgE}$ and contact dermatitis sensitized with oxazolone. Its genuine ginsenosides Rg3, Rf, and Rh2 also showed an anti-PCA reaction and anti-contact dermatitis effects. In particular, these ginsenosides, except for ginsenoside $\mathrm{Rg} 3$, inhibited the release of $\beta$-hexosaminidase from RBL-2H3 cells, although KRGS did not. This result suggests that the content of active ginsenosides in KRGS is low and, if its inactive saponins are orally administered, the ginsenosides may be metabolized by intestinal microflora and express the anti-PCA reaction, as previously reported. ${ }^{16-18)}$ Azelastine is a representative antiallergic drug that not only acts an $\mathrm{H}_{1}$-receptor antagonist but also decreases mediator release from mast cells and basophils. ${ }^{26,27)}$ We also confirmed that azelastine inhibited the release of $\beta$-hexosaminidase from RBL-2H3 cells and exhibited antihistamine action during the present investigation using guinea pig ileum, as previously reported. ${ }^{17,26)}$ However, ginsenosides $\mathrm{Rg} 3, \mathrm{Rf}$, and $\mathrm{Rh} 2$ at a concentration of $0.2 \mathrm{~mm}$ exhibited almost no antihistamine action (data not shown), although Tachikawa et al. reported that ginsenoside $\mathrm{Rg} 3$ weakly inhibited histamine-induced ileum contractions in the guinea pig. ${ }^{14)}$ These ginsenosides did not scavenge the superoxide anion, although some antiallergic and antipsoriatic agents are scavengers of active oxygen species. In the previous study, the membrane-stabilizing effects of ginsenoside $\mathrm{Rh} 2$ were greater than those of DSCG. ${ }^{28)}$ These results suggest that the inhibitory action of these ginsenosides on the release of $\beta$-hexosaminidase may be due to protection of the degranulation response by antigen-IgE, These ginsenosides also showed the most potent inhibitory activity against the PCA reaction.

Contact dermatitis is accompanied by sustained swelling, predominant epidermal hyperplasia, and marked infiltration of inflammatory cells consisting of monocytes, granulocytes, and macrophages, but not eosionphils. In the present study, oxazolone-induced dermatitis was also accompanied by sustained swelling and predominant epidermal hyperplasia as reported by Fujii et al. ${ }^{21)}$ IFN- $\gamma$ and TNF- $\alpha$, which are cytokines involved in chronic inflammatory skin disease, ${ }^{29-31)}$ and COX-2, which is an acute marker of acute inflammatory disease, were induced. COX-2, an inducible isoform of COX, is upregulated in skin inflammation and carcinogenesis. Hernandez et al. reproted that COX-2 was induced in angiogenesis-related diseases such as rheumatoid arthritis and psoriasis. ${ }^{32)}$ The ginsenosides Rf, Rg3, and Rh2 significantly inhibited sustained swelling (thickness) of mice ears induced by oxazolone as well as mRNA levels of COX-2. Furthermore, these ginsenosides significantly inhibited mRNA levels of TNF- $\alpha$ and IL- $1 \beta$ produced by macrophages. In the previous study, these ginsenosides inhibited $\mathrm{NO}$ and prostaglandin $\mathrm{E}_{2}$ biosynthesis in LPS-induced RAW264.7 cells. However, these ginsenosides did not inhibit the activities of COX-1 and $-2 .{ }^{18)}$ These findings support the hypothesis that these ginsenosides inhibit the expression levels of iNOS and COX-2 proteins in RAW264.7 cells induced by LPS. KRGS and ginsenosides potently inhibited the increase in oxazolone-induced IFN- $\gamma$ mRNA level but weakly inhibited the increase in IL-4 mRNA level produced by Th2 cells. These results suggest that these ginsenosides can improve chronic and inflammatory skin disorders, contact dermatitis, or psoriasis by the regulation of COX-2, TNF- $\alpha$, and IL- $1 \beta$ produced by macrophages and IFN- $\gamma$ and IL- 4 produced by Th cells. We therefore believe that KRGS and its genuine ginsenosides $\mathrm{Rg} 3, \mathrm{Rf}$, and $\mathrm{Rh} 2$ have extensive antiallergic and anticontact dermatitis activities.

Aknowledgement This work was supported by a grant from the Korea Ginseng Society (2004).

\section{REFERENCES}

1) Shibata S., Fujita M., Itokawa H., Tanaka O., Ishii T., Chem. Pharm. Bull., 11, 759-764 (1963). 
2) Tanaka N., Tanaka O., Shibata S., Chem. Pharm. Bull., 20, 12121216 (1972).

3) Kitagawa I., Yoshikawa M., Yoshihara M., Hayashi T., Taniyama T., Yakugaku Zasshi, 103, 612-622 (1983).

4) Kown S. W., Han S. B., Park I. H., Kim J. M., Park M. K., Park J. H., J. Chromatogr. Ser. A, 921, 335-339 (2001).

5) Kim W. Y., Kim J. M., Han S. B., Lee S. K., Kim N. D., Park M. K., Kim C. K., Park J. H., J. Nat. Prod., 63, 1702-1704 (2000).

6) Austin L. M., Ozawa M., Kikuchi T., Walters I. B., Krueger J. G., J. Invest. Dermatol., 113, 752-759 (1999).

7) Nicoloff B. J., Arch. Dermatol., 127, 871-884 (1991).

8) Hernandez G. L., Volpert O. V., Iniguez M. A., Lorenzo E., MartinezMartinez S., Grau R., Fresno M., Redondo J. M., J. Exp. Med., 193, $607-620$ (2001).

9) Fujii Y., Takeuchi H., Tanaka K., Sakuma S., Ohkubo Y., Mutoh S., Eur. J. Pharmacol., 456, 115-121 (2002).

10) Wu J. Y., Gardner B. H., Murphy C. I., Seals J. R., Kensil C. R., Recchia J., Beltz G. A., Newman G. W., Newman M. J., J. Immunol., 148 1519-1525 (1992).

11) Bae E. A., Han M. J., Choo M. K., Park S. Y., Kim D. H., Biol. Pharm. Bull., 25, 58-63 (2002).

12) Kim N. D., Kang S. Y., Kim M. J., Park J. H., Schini-Kerth V. B., Eur. J. Pharmacol., 367, 51-57 (1999).

13) Wakabayashi C., Hasegawa H., Murata J., Saiki I., Oncol. Res., 9, $411-417$ (1998).

14) Tachikawa E., Kudo K., Harada K., Kashimoto T., Miyate Y., Kakizaki A., Takahashi E., Eur. J. Pharmacol., 369, 23-32 (1999).

15) Ro J. Y., Ahn Y. S., Kim K. H., Int. J. Immunopharmacol., 20, 625641 (1998)

16) Park E. K., Choo M. K., Han M. J., Kim D. H., Int. Arch. Allergy Im- munol., 133, 113-120 (2004)

17) Choo M. K., Park E. K., Han M. J., Kim D. H., Planta Med., 69, 518 522 (2003).

18) Park E. K., Choo M. K., Kim E. J., Han M. J., Kim D. H., Biol. Pharm. Bull., 26, 1581-1584 (2003)

19) Choi O. H., Kim J. H., Kinet J. P., Nature (London), 380, 634-636 (1996).

20) Katayama S., Shionoya H., Ohtake S., Microbiol. Immunol., 22, 89101 (1978).

21) Fujii Y., Takeuchi H., Tanaka K., Sakuma S., Ohkubo Y., Mutoh S., Eur. J. Pharmacol., 456, 115-121 (2002).

22) Chi Y. S., Lim H., Park H., Kim H. P., Biochem. Pharmacol., 66, 1271-1278 (2003).

23) Ishihara T., Kohno K., Ushio S., Iwaki K., Ikeda M., Kurimoto M., Eur. J. Pharmacol., 407, 197-204 (2000).

24) Wuthrich B., Int. Arch. Allergy Appl. Immunol., 90 (Suppl. 1), 3-10 (1989).

25) Stevens R. L., Austen K. F., Immunol. Today, 10, 381-386 (1989).

26) Akagi M., Mio M., Tasaka K., Agents Actions, 13, 149-156 (1983).

27) Tasaka K., Mio M., Okamoto M., Ann. Allergy, 56, 464-469 (1986).

28) Cox J. S. G., Nature (London), 216, 1326-1329 (1967).

29) Abd-El-Aleem S. A., Feguson M. W., Appleton I., Bhowmick A., McCollum C. N., Ireland G. W., J. Pathol., 195, 616-623 (2001).

30) Bruch-Gerharz D., Fehsel K., Suschek C., Michel G., Ruzicka T., Kolba-Bachofen V., J. Exp. Med., 184, 2007-2012 (1996).

31) Bruch-Gerharz D., Ruzicka T., Kolb-Bachofen V., J. Invest. Dermatol., 110, 1-7 (1998).

32) Hernandez G. L., Volpert O. V., Iniguez M. A., Lorenzo E., MartinezMartinez S., Grau R., Fresno M., Redondo J. M., J. Exp. Med., 193, $607-620(2001)$. 